\title{
Non ABL-directed inhibitors as alternative treatment strategies for chronic myeloid leukemia
}

\author{
Michele Massimino ${ }^{1,2 \dagger}$, Stefania Stella ${ }^{1,2 \dagger}$, Elena Tirrò ${ }^{1,2}$, Chiara Romano ${ }^{1,2}$, Maria Stella Pennisi ${ }^{1,2}$, Adriana Puma ${ }^{1,2}$, \\ Livia Manzella ${ }^{1,2}$, Antonino Zanghi ${ }^{3}$, Fabio Stagno ${ }^{4}$, Francesco Di Raimondo ${ }^{4,5}$ and Paolo Vigneri ${ }^{1,2^{*}}$ (D)
}

\begin{abstract}
The introduction of ABL Tyrosine Kinase Inhibitors (TKIs) has significantly improved the outcome of Chronic Myeloid Leukemia (CML) patients that, in large part, achieve satisfactory hematological, cytogenetic and molecular remissions. However, approximately 15-20\% fail to obtain optimal responses according to the current European Leukemia Network recommendation because of drug intolerance or resistance. Moreover, a plethora of evidence suggests that Leukemic Stem Cells (LSCs) show BCR-ABL1-independent survival. Hence, they are unresponsive to TKIs, leading to disease relapse if pharmacological treatment is discontinued. All together, these biological events generate a subpopulation of CML patients in need of alternative therapeutic strategies to overcome TKI resistance or to eradicate LSCs in order to allow cure of the disease. In this review we update the role of "non ABL-directed inhibitors" targeting signaling pathways downstream of the BCR-ABL1 oncoprotein and describe immunological approaches activating specific T cell responses against CML cells.
\end{abstract}

Keywords: CML, BCR-ABL1, Therapeutic strategies, Immunological approaches

\section{Background}

Chronic Myeloid Leukemia (CML) is a myeloproliferative disorder characterized by neoplastic transformation of the Hematopoietic Stem Cell (HSC) which displays a cytogenetic marker derived from a reciprocal t9;22 translocation [1]. The ensuing Philadelphia (Ph) chromosome leads to the formation of the $B C R-A B L 1$ fusion oncogene encoding for a multi-domain BCR-ABL1 oncoprotein $[2,3]$. BCRABL1 oncoprotein is the molecular hallmark of CML displaying constitutive tyrosine kinase activity that induces the activation of several intracellular pathways such as phosphoinositide 3-kinase (PI3K)/murine thymoma viral oncogene homolog (AKT)/mammalian target of rapamycin (mTOR), Rat Sarcoma proto-oncogene (RAS)/extracellular signal-regulated kinase (ERK) and Janus Kinases (JAK)/Signal Transducer and Activators of Transcription

\footnotetext{
* Correspondence: pvigneri@libero.it

${ }^{\dagger}$ Equal contributors

'Department of Clinical and Experimental Medicine, University of Catania, Via Santa Sofia, 78, Catania 95123, Italy

${ }^{2}$ Center of Experimental Oncology and Hematology, A.O.U. Policlinico Vittorio Emanuele, Via Santa Sofia, 78, 95123 Catania, Italy

Full list of author information is available at the end of the article
}

(STATs). Furthermore, BCR-ABL1-dependent improper signaling inhibits apoptosis and increases the proliferation rate of leukemic cells [4-7].

In 2001 the introduction of Imatinib Mesylate (IM), a semi-specific BCR-ABL1 tyrosine kinase inhibitor, improved the outcome of CML patients in chronic phase, generating unprecedented rates of hematologic, cytogenetic and molecular response [8-10]. Indeed, patients receiving IM $400 \mathrm{mg} /$ daily in the IRIS (International Randomized Study of Interferon and STI571) study, achieved 83.3\% 10years survival [11]. Despite these excellent results, approximately 15-20\% CML patients fail to achieve an optimal response as defined by the current European Leukemia Net (ELN) recommendations [11-14].

Several biological mechanisms responsible for IM failure have been described including BCR-ABL1-dependent and -independent mechanisms.

The former include: $i$ ) mutations in the ABL kinase domain which prevent TKI binding [15]; ii) amplification of the BCR-ABL1 oncogene [16, 17]; iii) high expression levels of the BCR-ABL1 mRNA [18]. 
The latter comprise: i) up-regulation of drug efflux pumps [19]; ii) down regulation of drug influx transporters [20]; iii) Lyn overexpression (Src-family kinase protein) [21] and $i v$ ) other BCR-ABL1-independent mechanisms [22].

To overcome IM-resistance, more potent secondgeneration (2G i.e. Dasatinib - DAS, Nilotinib - NIL, Bosutinib - BOS) and third-generation (3G i.e. Ponatinib - PON) TKIs have been developed and approved for the treatment of the disease [23-26].

However, while 2G and 3G TKIs present higher BCRABL1 inhibitory activity if compared to IM, they have failed to generate meaningful survival advantages for CML patients [27-30]. Moreover, it is now apparent that, despite complete inhibition of BCR-ABL1 kinase activity, TKIs are unable to eliminate quiescent Leukemic Stem Cells (LSCs) $[4,31,32]$, as these cells are not "oncogene addicted" and therefore require alternative treatment strategies [32, 33].

In this review, we provide an update on the current knowledge of non ABL-directed inhibitors and immunologicaltargeting approaches as treatment strategies for CML patients achieving unsatisfactory responses to TKIs. In detail, we will focus on findings generated in primary CML cells, CML murine models and clinical trials.

\section{Farnesyl transferase inhibitors}

Farnesyl Transferase Inhibitors (FT-Is) inhibit farnesyl transferase activity preventing isoprenoid-group transfer on different protein targets $[34,35]$. Isoprenoid-group trasferring is a post-transcriptional modification that causes membrane migration of different proteins, such as RAS, resulting in their activation [36]. Activated RAS migrates in cellular membranes forming RAS-GTP which actives ERKand AKT- dependent signaling modulating cell cycle progression, survival and proliferation. Improper RAS activation is common in several cancer types including CML [37], and different FT-Is were developed as anti-neoplastic drugs $[34,38,39]$.

In CML, constitutive RAS activation is promoted by BCRABL1 interaction with Grb2 (Growth factor receptor bound protein), SOS (Son Of Sevenless) and Gab2 (Grb2-associated binder 2) and plays a critical role in leukemogenesis $[2,40]$ (Fig. 1a). Tipifarnib (R115777) and Lonafarnib (SCH66336) are two potent and selective FT-Is with potential antileukemic activity in CML patients [41].

\section{Tipifarnib (R115777)}

Clinical data obtained from twenty-two CML patients with chronic or advanced disease that had failed Interferonalpha (INF $\alpha$ ) treatment demonstrated that Tipifarnib, as a single agent, induced complete or partial hematological responses and transient minor cytogenetic responses with a median duration of only 9 weeks [42]. In Phase I trials (NCT00040105), CML patients that had failed IM (50\% with ABL kinase domain mutations), were treated with Tipifarnib in combination with IM. Co-treatment showed hematological and cytogenetic responses in $76 \%$ and $36 \%$ of patients, respectively. Moreover, four patients in cytogenetic remission (CyR) presented a BCR-ABL1 mutation ( $n=1$ T315I, $n=2 \mathrm{M} 244 \mathrm{~V}, n=1 \mathrm{E} 255 \mathrm{~K}$ ) [43].

\section{Lonafarnib (SCH66336)}

A pilot study investigated Lonafarnib efficacy in CML patients resistant or intolerant to IM. Only two of thirteen enrolled subjects showed hematological responses [44]. However, Lonafarnib administrated at different doses, showed greater efficacy when used in combination with IM. In particular, a Phase I study (NCT00047502) recruited CML patients who had failed IM observing hematological and cytogenetic responses in $35 \%$ of patients [45].

In summary, these data demonstrate that FT-I monotherapy showed little benefit for CML patients. However, their combination with IM may prove useful for CML subjects unresponsive to IM.

\section{mTOR inhibitors}

mTOR Inhibitors (mTOR-Is) target the mammalian Target of Rapamycin (mTOR) [46], a serine/threonine kinase regulating cellular proliferation and metabolism [47] (Fig. 1b). Constitutive mTOR activation has been observed in different leukemia types, including CML [48]. BCR-ABL1 induces the $\mathrm{PI} 3 \mathrm{~K} / \mathrm{AKT}$ pathway that results in mTOR phosphorylation, favoring tumor transformation $[2,48]$. Several manuscripts have demonstrated the efficacy of mTOR-Is on primary and immortalized BCR-ABL-positive cell lines alone or in combination with TKIs $[46,49,50]$.

\section{Rapamycin (Sirolimus)}

Rapamycin induces mTOR dephosphorylation resulting in reduced CML cell viability [51] and increased IM efficacy in resistant cells $[52,53]$. To date, only one clinical trial is underway to evaluate the therapeutic potentials of Rapamycin in combination with DNA damaging agents such as Cytarabine or Etoposide in the accelerated or blast phase of CML (NCT00776373).

\section{Everolimus (RAD001)}

Everolimus blocks mTOR constitutive activation, reducing CML proliferation and increasing IM sensitivity $[54,55]$. Interestingly, unlike Rapamycin, Everolimus can overcome IM resistance in BCR-ABL-positive quiescent cells transplanted in mouse recipients [56].

Everolimus therapeutic efficacy in CML patients, both alone and in combination with IM, is being evaluated in different clinical trials (NCT00081874), (NCT00093639).

\section{BEZ235}

BEZ235 is a dual PI3K-mTOR inhibitor tested on BCRABL1-positive cell lines. Published data demonstrated that 


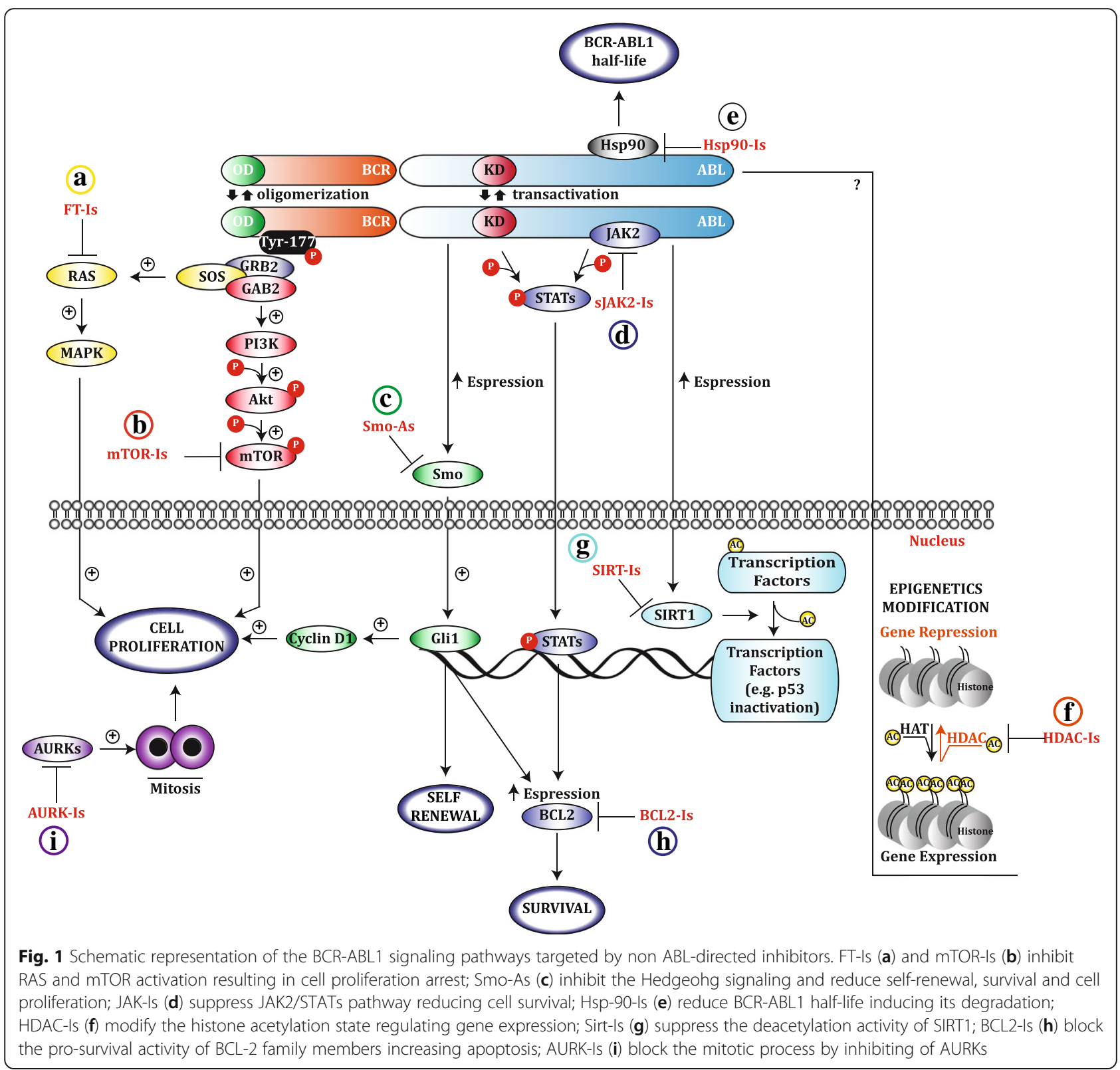

the combination of BEZ235 and NIL induces apoptosis, inhibits tumor growth in CML xenograft models and impairs NIL resistance $[57,58]$. A Phase I dose-finding study is being in patients with relapsed or refractory acute leukemia and advanced CML (NCT01756118).

\section{Temsirolimus}

To date, Temsirolimus is being investigated in a clinical trial in combination with IM (NCT00101088).

Even if the mTOR-Is have been thoroughly investigated in primary CML cells and in CML murine models recipient showing the ability to kill LSCs, to date, no data on CML patients are available, hence their therapeutic efficacy remains to be established.

\section{SMO antagonists}

Smo Antagonists (Smo-As) inhibit Smoothend (Smo), a putative seven-transmembrane domain receptor which is a component of the Hedgeohg (Hh) pathway involved in a broad number of cellular mechanisms such as stem cell renewal, cell proliferation and survival (Fig. 1c). Binding of Hh human ligands, (Sonic Hedgeohg SHh, Desert Hedgeohg DHh, Indian Hedgeohg IHh) with Ptch (seventransmembrane domain receptor Patched) causes a conformational change of Smo that actives the Gliomaassociated oncogene (Gli1) transcription factor leading to faster cellular division and reduced apoptosis [59]. Hence, deregulation of the Hh pathway plays a critical role in the tumorigenesis and cancer progression [60]. 
CML patients showed higher Hh expression compared to healthy donors and IM treatment did not reduce these mRNA levels, suggesting that Hh over-expression was not dependent on BCR-ABL1 kinase activity $[59,61]$.

Dierks et al. reported that Smo up-regulation improves expansion of BCR-ABL1-positive LSCs [62]. Moreover, invivo experimental models using CML CD34-positive cells demonstrated that Hh inhibition in Smo knock-out mice, compromised both leukemic stem cell renewal and propagation [63]. Hence, this pathway represents a potential therapeutic target in BCR-ABL1-positive cells.

Smo-As have been investigated in ex-vivo studies as well as in several clinical trials.

\section{LDE225 (Sonidegib/Erismodegib/Odomzo)}

LDE225 significantly reduced colony forming ability and re-plating efficiency of CML CD34-positive cells and also decreases their Long Term Culture - Initiating Cell (LTC-IC) frequency. Furthermore, the combination of LDE225 with NIL reduced the engraftment of CML CD45-positive cells in NSG (NOD scid gamma) mice. [64]. At the present time, the LDE225-NIL combination is under investigation in a clinical trial enrolling patients that have failed at least one TKI (NCT01456676).

\section{BMS833923 (XL139)}

Two clinical trials have evaluated the efficacy of BMS833923 in CML. In the first study (NCT01218477) CML and Ph + Acute Lymphoblastic Leukemia (ALL) patients resistant to IM or NIL were exposed to the combination of BMS833923 and DAS. Only 1 of 27 patients in chronic phase attained a complete cytogenetic response while no patients with $\mathrm{Ph}+$ ALL or advanced CML displayed any clinical benefit [65]. In the second study (NCT01357655), newly diagnosed CP-CML patients were enrolled but no participants received the BMS8333923-DAS combination, as no recommended dose of the Smo-A drug could be found.

\section{PF-04449913 (Gasdegib)}

In preclinical studies, PF-04449913 impaired the multi drug resistance (MDR) mechanism in LSCs by down-regulating the BCL2 (B-Cell Lymphoma 2) and/or ABCA2 (ATPBinding Cassette sub-family A member 2) oncogenes [66]. Furthermore, in CML xenograft models, treatment with PF-04449913 reduced the expansion of the leukemic stem cell suggesting a potential role for this compound in CML [67]. A Phase I dose escalation protocol (NCT00953758) investigated PF-04449913 safety in patients with different mieloproliferative disorders including CML, finding good tolerability at a dose which reduced Gli1 expression by Taqman array cards [68]. However, additional investigations are needed before this molecule can be considered for further development.
In conclusion, data obtained by ex-vivo studies or in mouse models suggest that inhibition of the Hh pathway interferes with both self-renewal and propagation of pluripotent BCR-ABL1-positive hematopoietic cells. Unfortunately, the unsatisfactory results obtained in CML patients currently preclude any significant role for these drugs in CML treatment.

\section{JAK2 inhibitors}

JAK2 inhibitors (JAK2-Is) suppress JAK2 catalytic activity that modulates STATs transcription factors regulating the expression of genes involved in cell proliferation, differentiation and apoptosis (Fig. 1d). Published data report that JAK2 interacts with the ABL C-terminal leading to its constitutive activation [69]. Neviani and colleagues have demonstrated that, BCR-ABL1 induces constitutive JAK2 activation in quiescent leukemic cells in a kinase independent manner, reducing the activity of the Protein Phosphatase 2A (PP2A) tumor suppressor. Furthermore, PP2A reactivation by the small molecule FTY720, reduced JAK2 activation impairing stem cell self-renewal and overcoming TKI resistance [70].

JAK2 inhibitors (JAK2-Is) have also been combined with IM, NIL and DAS killing CML cells and restoring TKI-sensitivity in resistant CML cell lines [71-73].

\section{Ruxolitinib}

Using a combination of Ruxolitinib with NIL, Gallipoli and colleagues observed an increased apoptotic rate in CML cell lines and a reduction of the leukemic engraftment in CML murine models [74]. These data were supported by a Phase I study where CML patients exposed to Ruxolitinb and NIL achieved $\geq 1$-log reduction in $B C R-A B L 1$ mRNA levels [75]. Several clinical trials are presently ongoing with Ruxolitinb alone or in combination with different TKIs in patients with advanced or resistant disease (NCT01702064), (NCT02253277), (NCT01751425), (NCT01914484), (NCT02973711).

\section{BMS-911543}

BMS-911543 displays cytotoxic effects in CML cell lines when administrated in combination with TKIs. Specifically, the exposure of BCR-ABL1-positive CD34 cells to BMS-911543 and DAS, eliminates TKI-insensitive leukemic stem cells, suggesting that the dual targeting strategy involving inhibition of both BCR-ABL1 and JAK2 may reduce the risk of developing TKI resistance in CML patients [76].

In conclusion, JAK2-Is combined with TKIs may represent a useful therapeutic approach for patients with advanced or resistant CML and may also contribute to the eradication of LSCs. 


\section{Hsp90 inhibitors}

Heat shock protein 90 (Hsp90) is a member of the Hsp family that encompass several ATP-dependent molecular chaperones constitutively expressed or induced by stress conditions such as hypoxia or toxin exposure (proteotoxic stress). They act preserving the correct folding of their client proteins and blocking their proteosomal degradation. Hsp90 shows high intratumoral expression and represents a poor prognostic indicator in cancer patients. Hsp90 inhibitors (Hsp90-Is) represent compounds of great interest as potential anti-leukemic agents [77-79].

Since, high Hsp90 expression inhibits BCR-ABL1 degradation, Hsp90-Is reduce BCR-ABL1 half-life (Fig. 1e) limiting the expansion of the leukemic clone [78]. The efficacy of four different Hsp90-Is has been evaluated in CML.

\section{7-AAG (Tanespimycin)}

In preclinical experiments, 17-allylamino-17-demethoxygeldanamycin (17-AAG) showed low efficacy when used as monotherapy but increased apoptotic rates when administrated in combination with Histone Deacetylase Inhibitors (HDAC-Is) or IM [80, 81]. Two Phase I CML clinical trials evaluated 17-AAG alone (NCT00093821) or in combination with cytarabine (NCT00098423).

\section{STA-9090 (Ganetespib)}

Using in-vitro CML experimental models, Ying et al., compared the anticancer properties of STA-9090 and 17-AAG. STA-9090 was more potent than 17-AAG in reducing the proliferation of CML cells, suggesting that it may be a useful agent for CML patients [82]. Both Phase I and Phase II trials are being STA-9090 efficacy in CML patients with advanced (NCT00964873) or relapsed (NCT00858572) disease.

\section{BIIB021}

BIIB021 reduces BCR-ABL1 protein expression thereby inducing significant growth inhibition in CML cell lines both sensitive and resistant to TKIs. In addition, BIIB021 also triggers autophagy by repressing the AKT-mTOR pathway and thus reactivating autophagy-inducer Ulk1 (unc-51 like autophagy activating kinase 1) [83].

\section{Novobiocin}

Novobiocin is a potent inhibitor of CML cell proliferation, with weak effects on CD34-positive cells derived from healthy donors. Furthermore, co-treatment of Novobiocin with IM reduced the proliferation of TKI-resistant cells, suggesting that this combination may be useful to overcome the mechanisms leading to IM failure [84].

In summary, Hsp90-Is generated promising results against primary and immortalized CML cells and in CML mouse models. However, the lack of data in CML patients requires further studies to asses the effectiveness of Hsp90-Is for CML treatment.
Histone Deacetilase and Sirtuin inhibitors

Histone Deacetilase Inhibitors (HDAC-Is) are smallmolecules that block HDAC enzymes involved in epigenetic modifications that regulate histone acetylation state. In general, while histone acetylation carried by Histone Acetyl Transferases (HATs) determines a chromatin permissive state that favors gene expression, histone deacetylation performed by HDACs, overturn this biological event inducing gene repression [85] (Fig. 1f).

Different HDAC isoforms, belonging to three different classes, are overexpressed in several cancer types. This up-regulation is associated with a reduction in both overall and disease-free survival suggesting a possible role for HDAC-Is as antitumor drugs [86]. Although no data support the involvement of HDAC in BCR-ABL1dependent transformation, many authors and several clinical trials have evaluated HDAC-Is activity in CML.

\section{SB939 (Pracinostat)}

One of the biological mechanisms responsible for TKI resistance, is the intronic deletion polymorphism of the BIM gene. SB939 restores IM sensitivity in CML CD34-positive cells displaying the intronic deletion polymorphism of the $B I M$ gene by repairing its pre-mRNA splicing, suggesting that patients presenting this polymorphism, may benefit from the combination of SB939 and IM [87]. Okabe et al. have associated two different HDAC-Is with Tozasertib (Aurora Kinase Inhibitor) in both immortalized and primary CML cells. They found that the synergic effect of SB939 or Vorinostat in combination with Tozasertib results in an increased apoptotic rate [88].

\section{Vorinostat}

Several manuscripts have found that the combination of Vorinostat with aurora kinase inhibitors (AURK-Is) or TKIs kills primary CML cells, Baf3 cells expressing different BCR-ABL1 mutants and also shows antileukemic properties in CML mouse models. [88, 89]. These data are also supported by CML clinical trials of Vorinostat in combination with the DNA damaging agent decitabine (NCT00275080), DAS (NCT00816283) or with the cyclindependent kinase inhibitor flavopiridol (NCT00278330).

\section{LBH589 (Panobinostat)}

LBH589 is an HDAC-I with potent antiproliferative activity in several cancer cell lines [90]. LBH589 inhibits Hsp90 promoting the proteosomal degradation of Hsp90 client proteins such as BCR-ABL1. Zaritskey et al. have investigated the therapeutic efficacy of this drug in a Phase II study (NCT00451035) including CML patients resistant to at least two previous TKIs. Of the twenty-nine recruited CML patients, only one showed a hematological remission with eradication of a T315I-positive clone in the absence of any CyR [91]. LBH589 has also been extensively studied as a 
potential anti-leukemic drug in combination with different TKIs. Matsuda and colleagues reported that LBH589 increased PON cytotoxicity in IM-resistant CML cell lines [92]. LBH589 is also being evaluated in combination with IM in CML patients in CyR with residual disease detectable by Q-PCR (NCT00686218).

These results suggest that HDAC-Is have questionable efficacy as single agents while they may be promising therapeutic agents when administrated in combination with additional anti-cancer drugs in patients failing TKIs.

Sirtuin Inhibitors (Sirt-Is) are a broad range of pharmaceutical agents inhibiting class III HDAC enzymes called Sirtuins (SIRTs) (Fig. 1g). These proteins play a key role in both healthy and cancer cells by mediating changes in the activation of oxidative stress. In mammals, seven SIRTs (SIRT1-SIRT7) have been identified which display a conserved core $\mathrm{NAD}^{+}$-binding domain and exhibit deacetylation and ADP-ribosylation activities [93]. Among all sirtuins, SIRT1 has been investigated in different hematological malignances including CML [94]. SIRT1 is overexpressed in primary and immortalized CML cells and a SIRT1 knock-out represses BCR-ABL1 transforming activity in mice recipients $[95,96]$. Sirt-Is such as tenovin-6, sirtinol and nicotinamide have been investigated in CML experimental models.

\section{Tenovin-6 (TV-6)}

Is a small-molecule that inhibits SIRT1 and SIRT2 resulting in p53 acetylation and activation [94]. The combined pharmacological inhibition of SIRT1 (by TV-6) and BCRABL1 (by IM) decreases cell proliferation, promotes apoptosis of CML progenitors and impairs CML engraftment in immunodeficient mice [95].

\section{Sirtinol}

Unlike TV-6, sirtinol is a SIRT1 specific inhibitor with anti-cancer properties in different tumors [97]. Wang et al. reported that SIRT1 overexpression promotes the acquisition of genetic mutations that, in turn, cause TKI resistance. Exposure to Sirtinol overcomes resistance to IM, NIL and DAS. [98].

In conclusion, the ability of Sirt-Is to maintain genomic stability and to reduce the LSCs pool, makes these compounds promising tools for CML treatment.

\section{BCL2 inhibitors}

Studies of gene and protein expression have shown that alternative splicing of multiple BCL2 family members facilitate the expansion of quiescent CML stem cells [99, 100] and reduce their apoptotic rate [101].

As BCL2 inhibitors (BCL2-Is) overturn these biological effects (Fig. 1h), they have been considered for the treatment of CML.

\section{Sabutoclax}

Sabutoclax, a pan-BCL2 inhibitor, sensitizes LSCs in the bone marrow niche to TKIs. A recent study has shown that exposure of CML CD34-positive cells to Sabutoclax increases DAS efficacy reducing engraftment of LSCs in mice [102].

\section{Obatoclax}

Preclinical evidence suggests that the pan-BCL2 inhibitor Obatoclax reduces colony formation in $\mathrm{Ph}+\mathrm{CD} 34$-positive progenitors [103]. A Phase I study has been designed to evaluate the safety of Obatoclax in different myleoproliferative disorders, including CML (NCT00438178).

\section{Venetoclax (ABT-199)}

Unlike Sabutoclax and Obatoclax, Venetoclax displays BCL2-selective antagonism with modest activity against CML progenitors when used as single agent. However, Ko and colleagues have recently shown that Venetoclax enhances IM cytotoxicity on CML progenitors [104].

In conclusion, although BCL2 inhibition may become a useful strategy in the future, the lack of clinical data in CML patients currently excludes this class of drugs from CML therapy.

\section{Aurora kinase inhibitors}

Aurora kinase inhibitors (AURK-Is) suppress the serinethreonine kinase activity of the AURK family that regulates cell division [105-107] (Fig. 1i). Three isoforms of the Aurora Kinases (AURORA-A -B and -C) modulate chromosome condensation and orientation playing a critical role in the control of the mitotic machinery. Hence, dysregulation of their activity generates chromosomal abnormalities driving DNA alterations responsible for cell transformation [107]. On the basis of these considerations, the AURKs have been considered potential therapeutic targets for the development of anticancer drugs [106]. Although, to date, the BCR-ABL1/AURK correlation with CML progression is unclear, the role of AURK-Is in CML treatment has been exstensively investigated [105].

\section{MK-0457 (VX-680 or Tozasertib)}

MK-0457 is active against immortalized CML cell lines and has also shown the ability to revert advanced CML patients expressing the T315I mutant to the chronic phase of the disease $[108,109]$. These promising data have resulted in the design of a Phase II study (NCT00405054) that showed cytogenetic and hematologic responses in advanced CML patients [110]. Finally, a Phase I dose escalation study of MK-0457 in combination with DAS is also ongoing (NCT00500006).

\section{PHA-739358 (Danusertib)}

Unlike MK-0457, PHA-739358 is a dual inhibitor of AURK and ABL (wild-type and mutated, including T315I), which 
showed promising activity both in leukemia and solid tumors. In detail, Danusertib exerts growth inhibition in immortalized BCR-ABL1-positive cells and in CML CD34positive progenitors derived from patients sensitive or resistant to TKIs [111, 112]. In a Phase I study, used as a single agent, PHA-739358 displayed acceptable toxicity and induced hematologic and cytogenetic responses in patients with advanced CML expressing the T315I mutant [113].

\section{AKI603}

AKI603 is an aurora kinase A inhibitor that exerts its antiproliferative activity by arresting CML cells sensitive or resistant to IM in the G2/M phase of the cell cycle. [114]. AKI603 also abrogates the growth of xenografted BCRABL1 T315I mutant cells in nude mice and restore IM ability to reduce their colony forming potential [115].

\section{MLN8237 (alisertib)}

Like AKI603, MLN8237 is an Aurora Kinase A inhibitor but it induces CML cell death by decreasing expression of Apollon, a protein that modulates cell division and apoptosis. In-vitro CML experimental models showed that MLN8273 induces apoptosis in cells expressing both wt and mutant BCR-ABL1. Moreover, MLN8273 improves NIL activity increasing CML CD34-positive cell death and reducing tumor growth in recipient mice [116].

\section{AT9283}

This multitarget kinase inhibitor, shows activity against CML cell lines and is able to reduce the engraftment of primary BCR-ABL1-positive cells [117]. A Phase I/II study is being the efficacy safety of AT9283 in patients with refractory hematological malignancies including CML (NCT00522990).

All together, these data indicate a likely role for AURK-Is as a useful therapeutic resource for patients with advanced CML resistant to TKIs.

\section{Protein translation inhibitor - Omacetaxine}

Omacetaxine binds the ribosome aminoacyl-tRNA acceptor site, thereby inhibiting the synthesis of different oncoproteins including BCR-ABL1 [118] (Fig. 2). Experimental data on primary BCR-ABL1-positive cells [119] and different clinical trials have demonstrated the efficacy of Omacetaxine as a therapeutic agent in CML.

Cortes and colleagues used Omacetaxine in CML patients resistant or intolerant to TKIs and obtained meaningful hematological and cytogenetic remissions [120, 121]. Furthermore, the same data were obtained in a Phase II study, (NCT00375219), enrolling patients with the T315I mutation [122].

Following these clinical data, the FDA approved Omacetaxine for the treatment of CML patients that do not benefit from TKIs with specific attention to patients carrying the T315I substitution.

Clinical studies and results from non ABL-directed Inhibitors are summarized in Table 1.

\section{Immunological approaches}

The immune response against cancer is impaired by an immune escape of the tumor cells [123]. Over the past decade, different investigators have studied vaccines activity in CML patients using BCR-ABL1 as specific antigen. Leukemia Associated Antigens (LAAs) and Dendritic Cell Vaccines (DCs) have also been investigated with the aim of inducing a T cell immune response against BCR-ABL1-expressing cells [99]. Furthermore, use of the immune-checkpoint blockade (ICB) has also been assessed.

\section{$B C R-A B L 1$ as a specific antigen}

Usually BCR-ABL1 immunogenic peptides are formed by an amino acid sequence of the e13a2 or e14a 2 breakpoint region [124]. Different authors have investigated the efficacy of BCR-ABL1 immune-peptides in CML.

The EPIC (Evaluation of Peptide Immunisation in CML) study accrued nineteen patients that were

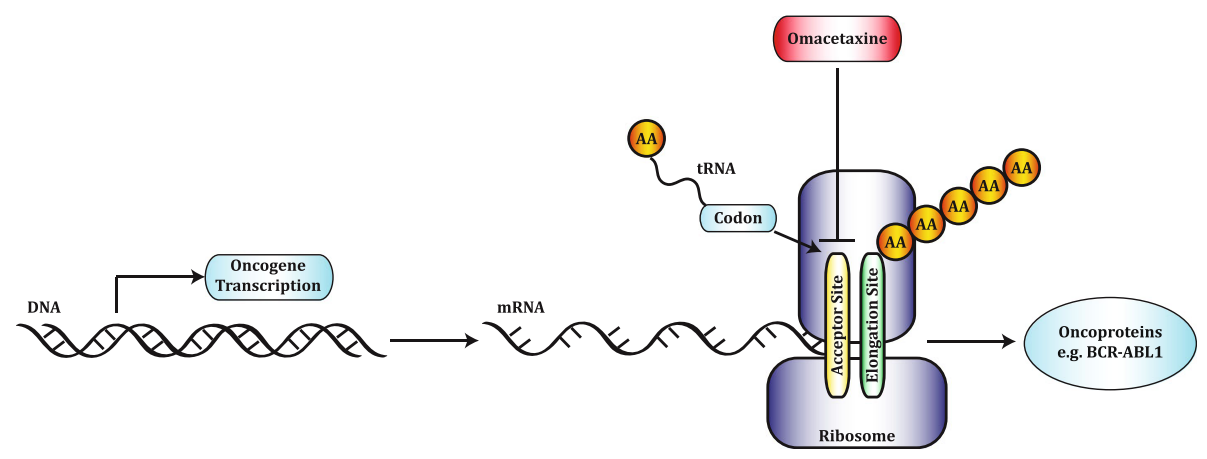

Fig. 2 Schematic representation of the mechanism of action of Omacetaxine. Oncogene transcription leads to mRNA translation that induce oncoprotein synthesis. Omacetaxine reduces BCR-ABL1 expression levels by blocking the ribosome t-RNA aminoacil acceptor site that results in a protein elongation arrest 
Table 1 Clinical studies and results from non ABL-directed Inhibitors

\begin{tabular}{|c|c|c|c|c|}
\hline Non ABL-directed Inhibitors & Clinical Study & Drugs Combination & Patient Characteristics (pts) & Results \\
\hline \multicolumn{5}{|l|}{ FT-Is } \\
\hline \multirow[t]{2}{*}{ Tipifarnib } & $(42)$ & - & $\begin{array}{l}\mathrm{CP}, \mathrm{AP}, \mathrm{BP} \\
(n=22)\end{array}$ & $\begin{array}{l}\text { HR: } 27 \% \text { CP, } 4 \% \text { AP } \\
\text { CyR: } 18 \% \text { CP }\end{array}$ \\
\hline & Phasel NCT00040105 & $\mathrm{IM}$ & $\begin{array}{l}\mathrm{CP} \text { having } \mathrm{ABL} \text { KD mutation } \\
(n=25)\end{array}$ & $\begin{array}{l}\text { HR: } 76 \% \\
\text { CyR: } 36 \%\end{array}$ \\
\hline \multirow[t]{2}{*}{ Lonafarnib } & Pilot Study ${ }^{(44)}$ & - & $\begin{array}{l}\text { CP, AP } \\
\text { IM resistant } \\
(n=13)\end{array}$ & HR: $8 \%$ CP, $8 \%$ AP \\
\hline & Phasel NCT00047502 $2^{(45)}$ & $\mathrm{IM}$ & $\begin{array}{l}\mathrm{CP}, \mathrm{AP}, \mathrm{BP} \\
(n=23)\end{array}$ & $\begin{array}{l}\text { HR: } 9 \% \text { CP, } 17 \% \text { AP/BP } \\
\text { CyR: } 4 \% \text { CP, 4\% AP/BP }\end{array}$ \\
\hline \multicolumn{5}{|l|}{ mTOR-Is } \\
\hline Rapamycin & Phasel/II NCT00776373 & Cytarabine Etoposide & $\mathrm{AP}, \mathrm{BP}$ & NDP \\
\hline \multirow[t]{2}{*}{ Everolimus } & Phasel/II NCT00081874 & - & $\mathrm{BP}$ & NDP \\
\hline & Phasel/II NCT00093639 & IM & $\mathrm{CP}$ & NDP \\
\hline BEZ235 & Phasel NCT01756118 & - & $\mathrm{AP}, \mathrm{BP}$ & NDP \\
\hline Temsirolimus & Phasel NCT00101088 & IM & $\mathrm{AP}, \mathrm{BP}$ & NDP \\
\hline \multicolumn{5}{|l|}{ Smo-As } \\
\hline LDE225 & Phasel NCT01456676 & NIL & $A P, B P$ & NDP \\
\hline \multirow[t]{2}{*}{ BMS833923 } & Phasel NCT1218477 & DAS & $\begin{array}{l}C P, A P, B P \\
(n=27)\end{array}$ & $\begin{array}{l}\text { CyR: } 4 \% \text { CP } \\
\text { PA/BP: no responded }\end{array}$ \\
\hline & Phasel NCT01357655 & DAS & $C P$ & No participants were enrolled \\
\hline PF-04449913 & Phase I NCT00953758 & - & $\mathrm{CP}$ & $\begin{array}{l}\text { Safety, Pharmacokinetics and } \\
\text { Pharmacodynamics study }\end{array}$ \\
\hline \multicolumn{5}{|l|}{ JAK2-IS } \\
\hline \multirow[t]{5}{*}{ Ruxolitinib } & Phasel NCT01702064 & NIL & $C P$ & ongoing \\
\hline & Phasel/II NCT02253277 & NIL & $\mathrm{CP}, \mathrm{Ph}+\mathrm{ALL}$ & ongoing \\
\hline & Phasel/II NCT01751425 & - & $C P$ with MRD & ongoing \\
\hline & Phasel/II NCT01914484 & NIL & $A P, B P, P h+A L L$ & ongoing \\
\hline & Phasel/II NCT02973711 & NIL & $\mathrm{CP}$ & ongoing \\
\hline \multicolumn{5}{|l|}{ Hsp90-Is } \\
\hline \multirow[t]{2}{*}{$17-A A G$} & Phasel NCT00093821 & - & $\mathrm{BP}$ & NDP \\
\hline & Phasel NCT00098423 & Cytarabine & $\mathrm{BP}$ & NDP \\
\hline \multirow[t]{2}{*}{ STA-9090 } & Phasel NCT00964873 & - & $\mathrm{BP}$ & NDP \\
\hline & Phasel NCT00858572 & - & refractory or relapsed CML & NDP \\
\hline \multicolumn{5}{|l|}{ HDAC-Is } \\
\hline \multirow[t]{3}{*}{ Vorinostat } & Phasel NCT00275080 & Decitabine & BP & NDP \\
\hline & Phasel NCT00816283 & DAS & $A P, B P$ & NDP \\
\hline & Phasel NCT00278330 & Flavopiridol & $\mathrm{BP}$ & NDP \\
\hline \multirow[t]{2}{*}{ LBH589 } & Phase II/III NCT00451035 & - & $\begin{array}{l}\text { CML TKIs resistant } \\
(n=29)\end{array}$ & HR: $3 \%$ \\
\hline & Phasel NCT00686218 & $\mathrm{IM}$ & $C P$ with MRD & NDP \\
\hline \multicolumn{5}{|l|}{ BCL2-Is } \\
\hline Obatoclax & Phasel NCT00438178 & - & $\mathrm{BP}$ & NDP \\
\hline \multicolumn{5}{|l|}{ AURK-IS } \\
\hline MK-0457 & Phase $\mid / / I^{(108)}$ & - & $\begin{array}{l}\text { AP, BP, Ph + ALL } \\
\text { All with T315l } \\
(n=18)\end{array}$ & $\begin{array}{l}\text { HR: } 39 \% \text { AP/BP } \\
\text { CyR: } 5 \% \text { Ph + ALL }\end{array}$ \\
\hline
\end{tabular}


Table 1 Clinical studies and results from non ABL-directed Inhibitors (Continued)

\begin{tabular}{|c|c|c|c|c|}
\hline Non ABL-directed Inhibitors & Clinical Study & Drugs Combination & Patient Characteristics (pts) & Results \\
\hline & Phasell NCT00405054 $4^{(110)}$ & - & $\begin{array}{l}\text { AP, BP, Ph + ALL } \\
\text { All with T315l } \\
(n=52)\end{array}$ & $\begin{array}{l}\text { CyR: } 8 \% \text { CP, } 6 \% \text { AP/BP } \\
\text { HR: } 4 \% \text { CP }\end{array}$ \\
\hline & Phasel NCT00500006 & DAS & $\mathrm{CP}$ & No Data Results Posted \\
\hline PHA-739358 & Phasel ${ }^{(113)}$ & - & $\begin{array}{l}\text { AP, BP } \\
(n=29)\end{array}$ & $\begin{array}{l}\text { HR: } 7 \% \text { AP/BP, } \\
7 \% \mathrm{Ph}+\mathrm{ALL} \\
\text { CyR: } 3 \% \mathrm{AP} / \mathrm{BP}, \\
3 \% \mathrm{Ph}+\mathrm{ALL} \\
\text { MR: } 3 \% \mathrm{Ph}+\mathrm{ALL}\end{array}$ \\
\hline AT9283 & Phasel NCT00522990 & - & $C P, A P, B P$ & NDP \\
\hline XL288 & Phasel NCT00464113 & - & $C P, A P, B P, P h+A L L$ & NDP \\
\hline \multicolumn{5}{|l|}{ PT-Is } \\
\hline \multirow[t]{3}{*}{ Omacetaxine } & Phasell $^{(120)}$ & - & $\begin{array}{l}\text { CP, TKIs resistant } \\
(n=46)\end{array}$ & HR: 67\%, CyR: 22 \\
\hline & Phasel//I ${ }^{(121)}$ & - & $\begin{array}{l}\text { CP, previously } \\
\text { exposed to TKls } \\
(n=81)\end{array}$ & HR: $81 \%$, CyR: $20 \%$ \\
\hline & Phasell NCT00375219 & - & $\begin{array}{l}\text { CP, BCR-ABL1 } \\
\text { T315I mutant } \\
(n=62)\end{array}$ & HR: $77 \%$, CyR: $22 \%$ \\
\hline
\end{tabular}

FT-Is Farnesyl Transferase Inhibitors, mTOR-Is mammalian Target of Rapamycin, Smo-As Smo Antagonists, JAK2-Is JAK2 Inhibitors, Hsp-90-Is Hsp-90 Inhibitors, HDAC-Is HDAC Inhibitors, BCL2-Is BCL2 Inhibitors, AURK-Is Aurora Kinase Inhibitors, PT-Is Protein Translation Inhibitors, HR Hematological Remission, CyR Cytogenetic Remission, CP Chronic Phase, AP Accelerated Phase, BP Blast Phase, NDP No Data Posted, MRD Minimal Residual Disease

vaccinated using e14a2 peptides. Thirteen patients, in cytogenetic remission after IM, showed late $\mathrm{T}$ cell immune response to BCR-ABL1 peptides and achieved a 1log decrease in BCR-ABL1 transcripts [125].

Nitin and colleagues investigated the efficacy of a mixture of immune-peptides in ten CML patients expressing e13a2 or co-expressing e13a2/e14a2 BCR-ABL1 isoforms. Three patients achieved a 1-log reduction in BCR-ABL1 mRNA levels and 3 additional patients developed a major molecular response. However, these responses have not been stable over time, suggesting that this therapeutic approach may only transiently improve molecular response in CML patients [126].

In a Phase 2 trial (NCT00267085), patients previously exposed to IM and showing complete cytogenetic remission but not a major molecular response were subjected to vaccination using the CMLVAXB2 or CMLVAXB3 peptides against the e13a2 and e14a2 BCR-ABL1 isoforms, respectively. Three patients out of ten achieved a 1-log reduction in BCR-ABL1 mRNA levels.

An interim analysis of a Phase II Multicenter GIMEMA CML Working Party trial reported that CML patients with minimal residual disease during IM treatment obtained a reduction of their disease burden after being exposed to the peptide vaccine CMLVAX100 (derived from BCR-ABL1 e14a2 isoform plus molgramostin, a leucocyte growth factor and QS-21 as immunoadjuvant) [127]. Furthermore, Bocchia et al. demonstrated that the combination CMVAX100 with GMCSF induced 50\% of $B C R-A B L 1$ mRNA levels reduction in patients previously exposed to IM and/or IFN [128].
The same group also described a patient that received a vaccine based on the e13a2 BCR-ABL1 isoform (CMLb2a2-25mer), achieving undetectable BCR-ABL1 transcripts in both peripheral blood and bone marrow [129].

In summary, the vaccines against BCR-ABL1 breakpoints have shown the ability to reduce residual disease in TKI-treated patients achieving cytogenetic remission. Several clinical trials are being this therapeutic approach (NCT00428077), (NCT00466726), (NCT00004052).

\section{Leukemia associated antigens (LAAs)}

Leukemia Associated Antigens (LAAs) are overexpressed in multiple leukemias including CML. Different LAAs have been identified as potential targets for vaccine synthesis and CML therapy $[124,130]$. Among them, the most promising are: $i$. the immunopeptide against the Wilms tumor oncogene (WT1), frequently overexpressed in CML patients. When this immunopeptide associated with IM, it may induce deep molecular response [131]. Currently, one clinical trial is evaluating the efficacy of this approach (NCT00004918); ii. K562/GM-CSF (GVAX), a cell-based vaccine derived from $\mathrm{K} 562$ cells genetically modified to produce granulocyte-macrophage colony-stimulating factor (GM-CSF) and a number of LAAs which recruit dendritic cells and activate T cell-mediated CML-specific immune responses. GAVX has been shown to reduce BCR-ABL1 transcript levels in CML patients [132].

Overall, the data generated in CML preclinical models and clinical report indicate a promising role for immune-dependent therapies for CML treatment. 


\section{DCs vaccine (dendritic cells)}

DCs are antigen-presenting cells that induce humoral and cellular immune responses. In CML, progenitor cells drive the formation of both leukemic clones and DCs. Since 98\% of them express the BCR-ABL1 oncoprotein, these cells represent a potential target for immunological therapy [124]. Previous published data indicates that CML-DCs present antigen-processing defects as a consequence of their reduced capacity to capture antigens if compared with normal DCs [133]. Furthermore, in two clinical trials, DCs injections did not generate any response [134, 135].

In conclusion, DCs-based vaccines appear unlikely to be of any meaningful value for CML treatment in the foreseeable future.

\section{Immune-checkpoint blockade (ICB)}

Cancer immunotherapy based on immune-checkpoint blockade (ICB) employs monoclonal antibodies against negative immune-regulator checkpoints such as cytotoxic T-lymphocyte antigen 4 (CTLA-4), programmed death 1 (PD-1) and its ligands (PD-L1, PD-L2) [136].

CML-specific cytotoxic T Lymphocytes (CTLs) show high PD-1 levels, whereas CML cells express PD-L1. In murine CML models, abrogation of PD-1 expression increases overall survival $[137,138]$ suggesting that blocking the PD-1/PD-L1 pathway may represent a new therapeutic strategy for CML.

Recently, Schutz demonstrated a correlation between CTLA-4-ligand CD86 expression and risk of disease relapse after TKI discontinuation. Indeed of 122 patients that had ceased TKIs, those expressing lower CD86 levels showed a $70 \%$ relapse-free survival suggesting that CD86 expression may be an early indicator of poor treatment-free remission probability [139].

A clinical trial (NCT01822509) is presently evaluating the efficacy of the combination ipilimumab (anti-CTLA-4) plus nivolumab (anti-PD-1) in patients with hematologic malignancies, including CML, relapsed after allogeneic hematopoietic cell transplantation.

Clinical studies and results from immune strategies are summarized in Table 2 .

\section{Conclusion}

TKIs that interfere with BCR-ABL1 signaling currently represent the first line and second line treatment of choice for most CML patients [26].

Table 2 Clinical studies and results from immune strategies

\begin{tabular}{|c|c|c|c|c|}
\hline Immune-peptide & Clinical Study & Drug Combinations & Patient Characteristics (pts) & Results (pts\%) \\
\hline \multicolumn{5}{|l|}{ BCR-ABL1 as specific antigen } \\
\hline e14a2 & Phasel//I ${ }^{(125)}$ & IM & CP in CyR $(n=19)$ & $(68 \%)<1-\log B A$ mRNA \\
\hline e13a2, e14a2 & Phasell ${ }^{(126)}$ & IM & CP in CyR $(n=10)$ & $\begin{array}{l}(30 \%)<1-\log \text { BA mRNA } \\
(30 \%) \text { MMR } \\
\text { (transient response) }\end{array}$ \\
\hline CMLVAXB2 (e13a2) CMLVAXB3 (e14a2) & Phasell NCT00267085 & IM & $C P$ in CyR $(n=10)$ & (30\%) $\downarrow<1-\log$ BA mRNA \\
\hline CMLVAX100 (e14a2) & Phasell ${ }^{(127)}$ & $\begin{array}{l}\text { IM } \\
\text { IFN }\end{array}$ & $\begin{array}{l}\text { CP in SRD (all } n=16) \\
\text { IM }(n=10) ; \text { IFN }(n=6)\end{array}$ & $\begin{array}{l}\text { IM: (50\%) CyR and } \\
\text { (30\%) BA UD } \\
\text { IFN: (83\%) CyR }\end{array}$ \\
\hline CMLVAX100-GMCSF & Phasell ${ }^{(128)}$ & $\begin{array}{l}\text { IM } \\
\text { IFN }\end{array}$ & $\begin{array}{l}\text { CP in MRD } \\
(n=43)\end{array}$ & (51\%) $\downarrow 50 \%$ BA mRNA \\
\hline CMLb2a2-25 (e13a2) & Case Study ${ }^{(129)}$ & - & $C P$ in CyR & $B A \cup D$ \\
\hline e13a2, e14a2 & Phasell NCT00428077 & - & $\begin{array}{l}\text { MRD } \\
(n=4)\end{array}$ & $(100 \%)<1-\log$ BA mRNA \\
\hline$e 13 a 2$ & Phasell NCT00466726 & IM & $C P$ in $M R D$ & NDP \\
\hline$e 13 a 2$ & $\begin{array}{l}\text { Phasell } \\
\text { NCT00004052 }\end{array}$ & - & $\mathrm{CP}$ in $\mathrm{HR}$ & NDP \\
\hline \multicolumn{5}{|l|}{ LAAs } \\
\hline \multirow[t]{2}{*}{ WT1 } & Case Study ${ }^{(131)}$ & IM & MRD & $\downarrow$ BA mRNA \\
\hline & $\begin{array}{l}\text { Phasel/II } \\
\text { NCT00004918 }\end{array}$ & - & $C P$ & NDP \\
\hline GVAX & (132) & IM & CyR $(n=19)$ & $(68 \%) \downarrow$ BA mRNA \\
\hline \multicolumn{5}{|l|}{ ICB } \\
\hline $\begin{array}{l}\text { Ipilimumab } \\
\text { Nivolumab }\end{array}$ & $\begin{array}{l}\text { Phasel } \\
\text { NCT01822509 }\end{array}$ & - & $\mathrm{CP}$ & ongoing \\
\hline
\end{tabular}

LAAs Leukemia Associated Antigens, ICB Immune-checkpoint blockade, HR Hematological Remission, CyR Cytogenetic Remission, CP Chronic Phase, AP Accelerated Phase, BP Blast Phase, NDP No Data Posted, MRD Minimal Residual Disease, UD Undetectable, SRD Stable Residual Disease 
However, BCR-ABL1-dependent or -independent resistance as well as BCR-ABL1-independent LSCs survival, partially undermine TKIs efficacy. Hence, a subgroup of CML patients is clearly in need of alternative therapeutic approaches. In this review we focused our attention on a range of pharmacological agents -non ABL-directed inhibitors- against different targets involved in BCR-ABL1dependent leukemic transformation.

We summarized data showing that FT-Is in combination with TKIs, Omacetaxine, AURK-Is and JAK2-Is have demonstrated efficacy in CML patients. We have also outlined clinical data demonstrating that vaccination against WT1 antigen, in combination with IM may represent a potential strategy to reduce $B C R-A B L 1$ mRNA levels or induce cytogenetic remissions. However, with the exception of Omacetaxine, none of the above indicated compounds have received approval for CML treatment. Furthermore, while there are several ongoing clinical trials evaluating the association of Ruxolitinib with NIL, at the current time it appears unlikely that other promising agents (i.e. FTY720, Hsp90-Is, AURK-Is and anti-WT1 antibodies) will undergo clinical development for the treatment of the disease.

The unsatisfactory results obtained with most of the non ABL-direct inhibitors has fostered additional research in the field that is currently investigating alternative strategies including: $i$ ) a WNT (homologus wingless)-targeting drug to modulate stem cell survival (PRI-724, clinical trial NCT01606579), ii) HDM2 (known as mdm-2, mouse double minute-2) inhibition to increase p53 half-life (RG7112, clinical trial NCT00623870), iii) a CXCR4 (CXC-chemokine receptor 4) antagonist as a hematopoiesis regulator (BL8040, clinical trial NCT02115672), iv) an ABL allosteric modulator (i.e. ABL001, clinical trial NCT02081378).

In summary, non ABL-directed inhibitors have often showed ability to overcome TKI resistance in primary CML cells or to eradicate the LSCs in mouse models. However, they displayed questionable efficacy in CML patients. Likewise, immunological approaches may be useful to improve molecular response, but this effect is often transient.

Finally, while the use of ICB may represent promising approaches to eradicate LSCs and predict molecular relapse of the disease after TKI discontinuation, these immune-based strategies seem far from achieving clinical relevance for CML therapy.

\section{Funding}

This work was supported by AIRC Grant (IG12958) to PV.

\section{Authors' contributions}

MM, SS, ET: drafted the manuscript. CR, MSP, AP: revised text, figures and tables. AZ, FS: clinical data support. LM, FDR, PV: project supervisors. All authors read and approved the final manuscript.

\section{Competing interests}

The authors declare that they have no competing interests.

\section{Publisher's Note}

Springer Nature remains neutral with regard to jurisdictional claims in published maps and institutional affiliations.

\section{Author details}

${ }^{1}$ Department of Clinical and Experimental Medicine, University of Catania, Via Santa Sofia, 78, Catania 95123, Italy. ${ }^{2}$ Center of Experimental Oncology and Hematology, A.O.U. Policlinico Vittorio Emanuele, Via Santa Sofia, 78, 95123 Catania, Italy. ${ }^{3}$ Department of Surgical Medical Sciences and Advanced Technologies, University of Catania, Via Santa Sofia, 78, Catania 95123, Italy. ${ }^{4}$ Division of Hematology and Bone Marrow Transplant, University of Catania, Via Santa Sofia, 78, Catania 95123, Italy. ${ }^{5}$ Department of Surgery, Medical and Surgical Specialties, University of Catania, Via Santa Sofia, 78, Catania 95123, Italy.

Received: 26 October 2017 Accepted: 1 February 2018

Published online: 19 February 2018

\section{References}

1. Rowley JD. Letter: a new consistent chromosomal abnormality in chronic myelogenous leukaemia identified by quinacrine fluorescence and Giemsa staining. Nature. 1973:243:290-3.

2. Ahmed W, Van Etten RA. Signal transduction in the chronic leukemias: implications for targeted therapies. Curr Hematol Malig Rep. 2013:8:71-80.

3. Fabio Stagno SS, Spitaleri A, Pennisi MS, Di Raimondo F, Vigneri P. Imatinib mesylate in chronic myeloid leukemia: frontline treatment and long-term outcomes. Expert Rev Anticancer Ther. 2016;16:273-8.

4. Tessa L, Holyoake GVH. Do we need more drugs for chronic myeloid leukemia? Immunol Rev. 2015;263:106-23.

5. Massimino M, Consoli ML, Mesuraca M, Stagno F, Tirro E, Stella S, Pennisi MS, Romano C, Buffa P, Bond HM, et al. IRF5 is a target of BCR$A B L$ kinase activity and reduces CML cell proliferation. Carcinogenesis. 2014;35:1132-43.

6. Ren R. Mechanisms of BCR-ABL in the pathogenesis of chronic myelogenous leukaemia. Nat Rev Cancer. 2005;5:172-83.

7. Stella S, Tirro E, Conte E, Stagno F, Di Raimondo F, Manzella L, Vigneri P. Suppression of survivin induced by a BCR-ABL/JAK2/STAT3 pathway sensitizes imatinib-resistant CML cells to different cytotoxic drugs. Mol Cancer Ther. 2013;12:1085-98.

8. Cortes J, Hochhaus A, Hughes T, Kantarjian H. Front-line and salvage therapies with tyrosine kinase inhibitors and other treatments in chronic myeloid leukemia. J Clin Oncol. 2011:29:524-31.

9. de Lavallade H, Apperley JF, Khorashad JS, Milojkovic D, Reid AG, Bua M, Szydlo R, Olavarria E, Kaeda J, Goldman JM, Marin D. Imatinib for newly diagnosed patients with chronic myeloid leukemia: incidence of sustained responses in an intention-to-treat analysis. J Clin Oncol. 2008;26:3358-63.

10. Druker BJ. Circumventing resistance to kinase-inhibitor therapy. N Engl J Med. 2006:354:2594-6.

11. Hochhaus A, Larson RA, Guilhot F, Radich JP, Branford S, Hughes TP, Baccarani M, Deininger MW, Cervantes F, Fujihara S, et al. Long-term outcomes of Imatinib treatment for chronic myeloid leukemia. N Engl J Med. 2017;376:917-27

12. Baccarani M, Deininger MW, Rosti G, Hochhaus A, Soverini S, Apperley JF, Cervantes F, Clark RE, Cortes JE, Guilhot F, et al. European LeukemiaNet recommendations for the management of chronic myeloid leukemia: 2013. Blood. 2013;122:872-84.

13. Stagno F, Stella S, Berretta S, Massimino M, Antolino A, Giustolisi R, Messina A, Di Raimondo F, Vigneri P. Sequential mutations causing resistance to both Imatinib Mesylate and Dasatinib in a chronic myeloid leukaemia patient progressing to lymphoid blast crisis. Leuk Res. 2008;32:673-4.

14. SGOB MD, Guilhot F, Goldman JM, Hochhaus A, Hughes TP, Radich JP, Hatfield AK, Mone M, Filian J, Reynolds J, Gathmann I, Larson RA, Druker BJ. International randomized study of interferon vs STI571 (IRIS) 8-year follow up: sustained survival and low risk for progression or events in patients with newly diagnosed chronic myeloid leukemia in chronic phase (CML-CP) treated with Imatinib. Blood. 2009;114:1126. 
15. Buffa P, Romano C, Pandini A, Massimino M, Tirro E, Di Raimondo F, Manzella L, Fraternali F, Vigneri PG. BCR-ABL residues interacting with ponatinib are critical to preserve the tumorigenic potential of the oncoprotein. FASEB J. 2014;28:1221-36.

16. Mahon FX, Deininger MW, Schultheis B, Chabrol J, Reiffers J, Goldman JM, Melo JV. Selection and characterization of BCR-ABL positive cell lines with differential sensitivity to the tyrosine kinase inhibitor STI571: diverse mechanisms of resistance. Blood. 2000;96:1070-9.

17. Philipp le Coutre ET, Varella-Garcia M, Barni R, Mologni L, Cabrita G, a, Marchesi E, Supino R, Gambacorti-Passerini C. Induction of resistance to the Abelson inhibitor STI571 in human leukemic cells through gene amplification. Blood. 2000;95:1758-66.

18. Vigneri P, Stagno F, Stella S, Cupri A, Forte S, Massimino M, Antolino A, Siragusa S, Mannina D, Impera SS, et al. High Bcr-Abl/Gusis levels at diagnosis of chronic phase $\mathrm{cml}$ are associated with unfavorable responses to standard-dose Imatinib. Clin Cancer Res. 2017;

19. Jordanides NE, Jorgensen HG, Holyoake TL, Mountford JC. Functional ABCG2 is overexpressed on primary CML CD34+ cells and is inhibited by imatinib mesylate. Blood. 2006;108:1370-3.

20. White DL, Saunders VA, Dang P, Engler J, Venables A, Zrim S, Zannettino A, Lynch K, Manley PW, Hughes T. Most CML patients who have a suboptimal response to imatinib have low OCT-1 activity: higher doses of imatinib may overcome the negative impact of low OCT-1 activity. Blood. 2007;110:4064-72.

21. Wu J, Meng F, Kong LY, Peng Z, Ying Y, Bornmann WG, Darnay BG, Lamothe B, Sun H, Talpaz M, Donato NJ. Association between imatinibresistant BCR-ABL mutation-negative leukemia and persistent activation of LYN kinase. J Natl Cancer Inst. 2008;100:926-39.

22. Wagle $M$, Eiring AM, Wongchenko M, Lu S, Guan Y, Wang Y, Lackner M, Amler L, Hampton G, Deininger MW, et al. A role for FOXO1 in BCR-ABL1independent tyrosine kinase inhibitor resistance in chronic myeloid leukemia. Leukemia. 2016;30:1493-501.

23. O'Hare T, Walters DK, Stoffregen EP, Jia T, Manley PW, Mestan J, CowanJacob SW, Lee FY, Heinrich MC, Deininger MW, Druker BJ. In vitro activity of Bcr-Abl inhibitors AMN107 and BMS-354825 against clinically relevant imatinib-resistant Abl kinase domain mutants. Cancer Res. 2005;65:4500-5.

24. Shah NP, Tran C, Lee FY, Chen P, Norris D, Sawyers CL. Overriding imatinib resistance with a novel ABL kinase inhibitor. Science. 2004;305: 399-401.

25. Tokarski JS, Newitt JA, Chang CY, Cheng JD, Wittekind M, Kiefer SE, Kish K, Lee FY, Borzillerri R, Lombardo $L$, et al. The structure of Dasatinib (BMS354825) bound to activated $A B L$ kinase domain elucidates its inhibitory activity against imatinib-resistant ABL mutants. Cancer Res. 2006;66:5790-7.

26. Gianantonio Rosti FC, Gugliotta G, Baccarani M. Tyrosine kinase inhibitors in chronic myeloid leukaemia: which, when, for whom? Nat Rev Clin Oncol. 2016;14:141-54

27. Cortes JE, Saglio G, Kantarjian HM, Baccarani M, Mayer J, Boque C, Shah NP, Chuah C, Casanova L, Bradley-Garelik B, et al. Final 5-year study results of DASISION: the Dasatinib versus Imatinib study in treatment-naive chronic myeloid leukemia patients trial. J Clin Oncol. 2016;34:2333-40.

28. Gambacorti-Passerini C, Cortes JE, Lipton JH, Dmoszynska A, Wong RS, Rossiev V, Pavlov D, Gogat Marchant K, Duvillie L, Khattry N, et al. Safety of bosutinib versus imatinib in the phase 3 BELA trial in newly diagnosed chronic phase chronic myeloid leukemia. Am J Hematol. 2014;89:947-53.

29. Hochhaus A, Saglio G, Hughes TP, Larson RA, Kim DW, Issaragrisil S, le Coutre PD, Etienne G, Dorlhiac-Llacer PE, Clark RE, et al. Long-term benefits and risks of frontline nilotinib vs imatinib for chronic myeloid leukemia in chronic phase: 5-year update of the randomized ENESTnd trial. Leukemia. 2016;30:1044-54.

30. Lipton JH, Chuah C, Guerci-Bresler A, Rosti G, Simpson D, Assouline S, Etienne G, Nicolini FE, le Coutre P, Clark RE, et al. Ponatinib versus imatinib for newly diagnosed chronic myeloid leukaemia: an international, randomised, open-label, phase 3 trial. Lancet Oncol. 2016; 17:612-21.

31. Corbin AS, Agarwal A, Loriaux M, Cortes J, Deininger MW, Druker BJ. Human chronic myeloid leukemia stem cells are insensitive to imatinib despite inhibition of BCR-ABL activity. J Clin Invest. 2011;121:396-409.

32. Hamilton A, Helgason GV, Schemionek M, Zhang B, Myssina S, Allan EK, Nicolini FE, Muller-Tidow C, Bhatia R, Brunton VG, et al. Chronic myeloid leukemia stem cells are not dependent on Bcr-Abl kinase activity for their survival. Blood. 2012;119:1501-10.
33. Saussele S, Richter J, Hochhaus A, Mahon FX. The concept of treatment-free remission in chronic myeloid leukemia. Leukemia. 2016;30:1638-47.

34. XYaJH JW. New tricks for human farnesyltransferase inhibitor: cancer and beyond. Med Chem Comm. 2017:8:841-5.

35. Rowinsky EK, Windle JJ, Von Hoff DD. Ras protein farnesyltransferase: a strategic target for anticancer therapeutic development. J Clin Oncol. 1999; 17:3631-52

36. Wang M, Casey PJ. Protein prenylation: unique fats make their mark on biology. Nat Rev Mol Cell Biol. 2016;17:110-22.

37. Samatar AA, Poulikakos PI. Targeting RAS-ERK signalling in cancer: promises and challenges. Nat Rev Drug Discov. 2014;13:928-42.

38. Appels NM, Beijnen JH, Schellens JH. Development of farnesyl transferase inhibitors: a review. Oncologist. 2005;10:565-78.

39. Downward J. Targeting RAS signalling pathways in cancer therapy. Nat Rev Cancer 2003:3:11-22.

40. Weisberg E, Manley PW, Cowan-Jacob SW, Hochhaus A, Griffin JD. Second generation inhibitors of $B C R-A B L$ for the treatment of imatinib-resistant chronic myeloid leukaemia. Nat Rev Cancer. 2007;7:345-56.

41. Melo JV, Chuah C. Novel agents in CML therapy: tyrosine kinase inhibitors and beyond. Hematology Am Soc Hematol Educ Program. 2008:427-35.

42. Cortes J, Albitar M, Thomas D, Giles F, Kurzrock R, Thibault A, Rackoff W, Koller C, O'Brien S, Garcia-Manero G, et al. Efficacy of the farnesyl transferase inhibitor R115777 in chronic myeloid leukemia and other hematologic malignancies. Blood. 2003;101:1692-7.

43. Cortes J, Quintas-Cardama A, Garcia-Manero G, O'Brien S, Jones D, Faderl S, Ebarb T, Giles F, Thomas D, Kantarjian H. Phase 1 study of tipifarnib in combination with imatinib for patients with chronic myelogenous leukemia in chronic phase after imatinib failure. Cancer. 2007;110:2000-6.

44. Borthakur G, Kantarjian H, Daley G, Talpaz M, O'Brien S, Garcia-Manero G, Giles F, Faderl S, Sugrue M, Cortes J. Pilot study of lonafarnib, a farnesyl transferase inhibitor, in patients with chronic myeloid leukemia in the chronic or accelerated phase that is resistant or refractory to imatinib therapy. Cancer. 2006;106:346-52.

45. Cortes J, Jabbour E, Daley GQ, O'Brien S, Verstovsek S, Ferrajoli A, Koller C, Zhu Y, Statkevich P, Kantarjian H. Phase 1 study of lonafarnib (SCH 66336) and imatinib mesylate in patients with chronic myeloid leukemia who have failed prior single-agent therapy with imatinib. Cancer. 2007:110:1295-302.

46. Teachey DT, Grupp SA, Brown VI. Mammalian target of rapamycin inhibitors and their potential role in therapy in leukaemia and other haematological malignancies. Br J Haematol. 2009;145:569-80.

47. Laplante M, Sabatini DM. mTOR signaling in growth control and disease. Cell. 2012;149:274-93.

48. Dinner S, Platanias LC. Targeting the mTOR pathway in leukemia. J Cell Biochem. 2016;117:1745-52.

49. Airiau K, Mahon FX, Josselin M, Jeanneteau M, Belloc F. PI3K/mTOR pathway inhibitors sensitize chronic myeloid leukemia stem cells to nilotinib and restore the response of progenitors to nilotinib in the presence of stem cell factor. Cell Death Dis. 2013:4:e827.

50. Badura S, Tesanovic T, Pfeifer H, Wystub S, Nijmeijer BA, Liebermann M, Falkenburg $\mathrm{JH}$, Ruthardt M, Ottmann OG. Differential effects of selective inhibitors targeting the PI3K/AKT/mTOR pathway in acute lymphoblastic leukemia. PLoS One. 2013;8:e80070.

51. Li J, Xue L, Hao H, Han Y, Yang J, Luo J. Rapamycin provides a therapeutic option through inhibition of mTOR signaling in chronic myelogenous leukemia. Oncol Rep. 2012;27:461-6.

52. Dengler J, von Bubnoff N, Decker T, Peschel C, Duyster J. Combination of imatinib with rapamycin or RAD001 acts synergistically only in Bcr-Abl-positive cells with moderate resistance to imatinib. Leukemia. 2005;19:1835-8.

53. Mohi MG, Boulton C, Gu TL, Sternberg DW, Neuberg D, Griffin JD, Gilliland DG, Neel BG. Combination of rapamycin and protein tyrosine kinase (PTK) inhibitors for the treatment of leukemias caused by oncogenic PTKs. Proc Natl Acad Sci U S A. 2004:101:3130-5.

54. Mancini M, Corradi V, Petta S, Martinelli G, Barbieri E, Santucci MA. mTOR inhibitor RAD001 (Everolimus) enhances the effects of imatinib in chronic myeloid leukemia by raising the nuclear expression of c-ABL protein. Leuk Res. 2010:34:641-8.

55. Mancini M, Petta S, Martinelli G, Barbieri E, Santucci MA. RAD 001 (everolimus) prevents $\mathrm{mTOR}$ and Akt late re-activation in response to imatinib in chronic myeloid leukemia. J Cell Biochem. 2010;109:320-8. 
56. Kuwatsuka Y, Minami M, Minami Y, Sugimoto K, Hayakawa F, Miyata Y, Abe A, Goff DJ, Kiyoi H, Naoe T. The mTOR inhibitor, everolimus (RAD001), overcomes resistance to imatinib in quiescent Ph-positive acute lymphoblastic leukemia cells. Blood Cancer J. 2011;1:e17.

57. Ding J, Romani J, Zaborski M, MacLeod RA, Nagel S, Drexler HG, Quentmeier H. Inhibition of PI3K/mTOR overcomes nilotinib resistance in BCR-ABL1 positive leukemia cells through translational down-regulation of MDM2. PLoS One. 2013:8:e83510.

58. Okabe S, Tauchi T, Tanaka Y, Kitahara T, Kimura S, Maekawa T, Ohyashiki K. Efficacy of the dual PI3K and mTOR inhibitor NVP-BEZ235 in combination with nilotinib against BCR-ABL-positive leukemia cells involves the ABL kinase domain mutation. Cancer Biol Ther. 2014;15:207-15.

59. Long B, Zhu H, Zhu C, Liu T, Meng W. Activation of the hedgehog pathway in chronic myelogeneous leukemia patients. J Exp Clin Cancer Res. 2011;30:8.

60. Rubin LL, de Sauvage FJ. Targeting the hedgehog pathway in cancer. Nat Rev Drug Discov. 2006;5:1026-33.

61. Chen Y, Peng C, Sullivan C, Li D, Li S. Critical molecular pathways in cancer stem cells of chronic myeloid leukemia. Leukemia. 2010;24:1545-54.

62. Dierks C, Beigi R, Guo GR, Zirlik K, Stegert MR, Manley P, Trussell C, SchmittGraeff A, Landwerlin K, Veelken $\mathrm{H}$, Warmuth M. Expansion of Bcr-Ablpositive leukemic stem cells is dependent on hedgehog pathway activation. Cancer Cell. 2008;14:238-49.

63. Zhao C, Chen A, Jamieson CH, Fereshteh M, Abrahamsson A, Blum J, Kwon HY, Kim J, Chute JP, Rizzieri D, et al. Hedgehog signalling is essential for maintenance of cancer stem cells in myeloid leukaemia. Nature. 2009;458:776-9.

64. Irvine DA, Zhang B, Kinstrie R, Tarafdar A, Morrison H, Campbell VL, Moka HA, Ho Y, Nixon C, Manley PW, et al. Deregulated hedgehog pathway signaling is inhibited by the smoothened antagonist LDE225 (Sonidegib) in chronic phase chronic myeloid leukaemia. Sci Rep. 2016;6:25476.

65. Shah JEC NP, Martinelli G, Douglas Smith B, Clarke E, Copland M, LSaM T. Dasatinib plus smoothened (SMO) inhibitor BMS-833923 in chronic myeloid leukemia $(\mathrm{CML})$ with resistance or suboptimal response to a prior tyrosine kinase inhibitor (TKI): phase I study CA180323. Blood. 2014;124:4539.

66. Cristina Papayannidis VG, lacobucci I, Durante S, Terragna C, Ottaviani E, Abbenante MC, Cattina F, Soverini S, Lama B, Toni L, Levin WJ, Courtney R, Baldazzi C, Curti A, Baccarani M, Jamieson C, Cortes JE, Oehler V, McLachlan K, van Arsdale T, Martinelli G. PF-04449913 reverts multi drug resistance (MDR) by a strong down-regulation of $A B C A 2$ and $B C L 2$ on leukemia stem cells in phase I acute myeloid leukemia and chronic myeloid leukemia treated patients. Blood. 2011;118:1429.

67. Sadarangani A, Pineda G, Lennon KM, Chun HJ, Shih A, Schairer AE, Court AC, Goff DJ, Prashad SL, Geron I, et al. GLI2 inhibition abrogates human leukemia stem cell dormancy. J Transl Med. 2015;13:98.

68. Martinelli G, Oehler VG, Papayannidis C, Courtney R, Shaik MN, Zhang X, O'Connell A, McLachlan KR, Zheng X, Radich J, et al. Treatment with PF04449913, an oral smoothened antagonist, in patients with myeloid malignancies: a phase 1 safety and pharmacokinetics study. The Lancet Haematology. 2015:2:e339-e346.

69. Danial NN, Rothman P. JAK-STAT signaling activated by Abl oncogenes. Oncogene. 2000;19:2523-31.

70. Neviani P, Harb JG, Oaks JJ, Santhanam R, Walker CJ, Ellis JJ, Ferenchak G, Dorrance AM, Paisie CA, Eiring AM, et al. PP2A-activating drugs selectively eradicate TKI-resistant chronic myeloid leukemic stem cells. J Clin Invest. 2013;123:4144-57.

71. Chen M, Gallipoli P, DeGeer D, Sloma I, Forrest DL, Chan M, Lai D, Jorgensen $\mathrm{H}$, Ringrose $\mathrm{A}$, Wang $\mathrm{HM}$, et al. Targeting primitive chronic myeloid leukemia cells by effective inhibition of a new AHI-1-BCR-ABL-JAK2 complex. J Natl Cancer Inst. 2013;105:405-23.

72. Quintarelli C, De Angelis B, Errichiello S, Caruso S, Esposito N, Colavita I, Raia M, Pagliuca S, Pugliese N, Risitano AM, et al. Selective strong synergism of Ruxolitinib and second generation tyrosine kinase inhibitors to overcome bone marrow stroma related drug resistance in chronic myelogenous leukemia. Leuk Res. 2014;38:236-42.

73. Traer E, MacKenzie R, Snead J, Agarwal A, Eiring AM, O'Hare T, Druker BJ, Deininger MW. Blockade of JAK2-mediated extrinsic survival signals restores sensitivity of CML cells to ABL inhibitors. Leukemia. 2012;26:1140-3.

74. Gallipoli P, Cook A, Rhodes S, Hopcroft L, Wheadon H, Whetton AD, Jorgensen HG, Bhatia R, Holyoake TL. JAK2/STAT5 inhibition by nilotinib with ruxolitinib contributes to the elimination of CML CD34+ cells in vitro and in vivo. Blood. 2014;124:1492-501.
75. Sweet LH KL, Sahakian E, Powers JJ, Nodzon L, Kayali F, Hyland K, Nelson A, Pinilla-Ibarz J. A Phase I Study of Ruxolitinib Plus Nilotinib in Chronic Phase CML Patients with Molecular Evidence of Disease. blood. 2016;128:1892.

76. Lin H, Chen M, Rothe K, Lorenzi MV, Woolfson A, Jiang X. Selective JAK2/ $A B L$ dual inhibition therapy effectively eliminates TKl-insensitive CML stem/ progenitor cells. Oncotarget. 2014;5:8637-50.

77. Schopf FH, Biebl MM, Buchner J. The HSP90 chaperone machinery. Nat Rev Mol Cell Biol. 2017;18:345-60.

78. Khajapeer KV, Baskaran R. Hsp90 inhibitors for the treatment of chronic myeloid leukemia. Leuk Res Treatment. 2015;2015:757694.

79. Bishop SC, Burlison JA, Blagg BS. Hsp90: a novel target for the disruption of multiple signaling cascades. Curr Cancer Drug Targets. 2007;7:369-88.

80. George P, Bali P, Annavarapu S, Scuto A, Fiskus W, Guo F, Sigua C, Sondarva G, Moscinski L, Atadja P, Bhalla K. Combination of the histone deacetylase inhibitor LBH589 and the hsp90 inhibitor 17-AAG is highly active against human CML-BC cells and AML cells with activating mutation of FLT-3. Blood. 2005;105:1768-76

81. Radujkovic A, Schad M, Topaly J, Veldwijk MR, Laufs S, Schultheis BS, Jauch A, Melo JV, Fruehauf S, Zeller WJ. Synergistic activity of imatinib and 17-AAG in imatinib-resistant CML cells overexpressing BCR-ABL-inhibition of Pglycoprotein function by 17-AAG. Leukemia. 2005;19:1198-206.

82. Ying W, Du Z, Sun L, Foley KP, Proia DA, Blackman RK, Zhou D, Inoue T, Tatsuta N, Sang J, et al. Ganetespib, a unique triazolone-containing Hsp90 inhibitor, exhibits potent antitumor activity and a superior safety profile for cancer therapy. Mol Cancer Ther. 2012;11:475-84.

83. He W, Ye X, Huang X, Lel W, You L, Wang L, Chen X, Qian W. Hsp90 inhibitor, BIIB021, induces apoptosis and autophagy by regulating mTORUlk1 pathway in imatinib-sensitive and -resistant chronic myeloid leukemia cells. Int J Oncol. 2016:48:1710-20.

84. Wu LX, Xu JH, Zhang KZ, Lin Q, Huang XW, Wen CX, Chen YZ. Disruption of the Bcr-Abl/Hsp90 protein complex: a possible mechanism to inhibit Bcr-Ablpositive human leukemic blasts by novobiocin. Leukemia. 2008;22:1402-9.

85. Ceccacci $\mathrm{E}$, Minucci S. Inhibition of histone deacetylases in cancer therapy: lessons from leukaemia. Br J Cancer. 2016;114:605-11.

86. West AC, Johnstone RW. New and emerging HDAC inhibitors for cancer treatment. J Clin Invest. 2014;124:30-9.

87. Rauzan M, Chuah CT, Ko TK, Ong ST. The HDAC inhibitor SB939 overcomes resistance to $B C R-A B L$ kinase inhibitors conferred by the BIM deletion polymorphism in chronic myeloid leukemia. PLoS One. 2017;12:e0174107.

88. Okabe S, Tauchi T, Tanaka Y, Kimura S, Maekawa T, Ohyashiki K. Activity of histone deacetylase inhibitors and an aurora kinase inhibitor in BCR-ABLexpressing leukemia cells: combination of HDAC and aurora inhibitors in BCR-ABL-expressing cells. Cancer Cell Int. 2013;13:32.

89. Okabe S, Tauchi T, Kimura S, Maekawa T, Kitahara T, Tanaka Y, Ohyashiki K. Combining the ABL1 kinase inhibitor ponatinib and the histone deacetylase inhibitor vorinostat: a potential treatment for BCR-ABL-positive leukemia. PLoS One. 2014;9:e89080.

90. Atadja P. Development of the pan-DAC inhibitor panobinostat (LBH589): successes and challenges. Cancer Lett. 2009;280:233-41.

91. Andrey Zaritskey GA, Lech Konopka, Jila Shamsazar, Priscille M. Bourquelot, Muhammad Jalaluddin, Martha Li, Anna Turkina, Gert J. Ossenkoppele, Stuart L. Goldberg and, Powell B: A phase II study of oral Panobinostat (LBH589) for chronic phase chronic myeloid leukemia (CML) with resistance to $\geq 2$ BCR-ABL tyrosine kinase inhibitors. Blood 2008, 112:4254.

92. Matsuda Y, Yamauchi T, Hosono N, Uzui K, Negoro E, Morinaga K, Nishi R, Yoshida A, Kimura S, Maekawa T, Ueda T. Combination of panobinostat with ponatinib synergistically overcomes imatinib-resistant CML cells. Cancer Sci. 2016;107:1029-38.

93. Chalkiadaki A, Guarente L. The multifaceted functions of sirtuins in cancer. Nat Rev Cancer. 2015;15:608-24.

94. Chen W, Bhatia R. Roles of SIRT1 in leukemogenesis. Curr Opin Hematol. 2013;20:308-13

95. Li L, Wang L, Li L, Wang Z, Ho Y, McDonald T, Holyoake TL, Chen W, Bhatia R. Activation of $\mathrm{p} 53$ by SIRT1 inhibition enhances elimination of CML leukemia stem cells in combination with imatinib. Cancer Cell. 2012;21:266-81.

96. Yuan H, Wang Z, Li L, Zhang H, Modi H, Horne D, Bhatia R, Chen W Activation of stress response gene SIRT1 by BCR-ABL promotes leukemogenesis. Blood. 2012;119:1904-14.

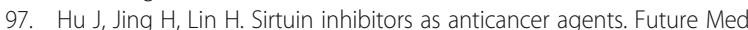
Chem. 2014;6:945-66. 
98. Wang Z, Yuan H, Roth M, Stark JM, Bhatia R, Chen WY. SIRT1 deacetylase promotes acquisition of genetic mutations for drug resistance in CML cells. Oncogene. 2013;32:589-98.

99. Ahmed W, Van Etten RA. Alternative approaches to eradicating the malignant clone in chronic myeloid leukemia: tyrosine-kinase inhibitor combinations and beyond. Hematology Am Soc Hematol Educ Program. 2013;2013:189-200.

100. Siddhartha Jaiswal DT, Miyamoto T, Akashi K, Lagasse E, Weissman IL. Expression of BCR ABL and BCL-2 in myeloid progenitors leads to myeloid leukemias. PNAS. 2003;100:10002-7.

101. Youle RJ, Strasser A. The BCL-2 protein family: opposing activities that mediate cell death. Nat Rev Mol Cell Biol. 2008;9:47-59.

102. Goff DJ, Court Recart A, Sadarangani A, Chun HJ, Barrett CL, Krajewska M, Leu H, Low-Marchelli J, Ma W, Shih AY, et al. A pan-BCL2 inhibitor renders bone-marrow-resident human leukemia stem cells sensitive to tyrosine kinase inhibition. Cell Stem Cell. 2013;12:316-28.

103. Soliera AR, Mariani SA, Audia A, Lidonnici MR, Addya S, Ferrari-Amorotti G, Cattelani S, Manzotti G, Fragliasso V, Peterson L, et al. Gfi-1 inhibits proliferation and colony formation of p210BCR/ABL-expressing cells via transcriptional repression of STAT 5 and Mcl-1. Leukemia. 2012;26:1555-63.

104. Tun Kiat Ko CTHC, Huang JWJ, Ng K-P, Tiong Ong S. The BCL2 inhibitor ABT-199 significantly enhances imatinibinduced cell death in chronic myeloid leukemia progenitors. Oncotarget. 2014;5:9033-8.

105. Alvarado Y, Cortés JE. Emerging role of aurora kinase inhibitors in chronic myeloid leukemia. Clin Leuk. 2007;1:325-30.

106. Bavetsias V, Linardopoulos S. Aurora kinase inhibitors: current status and outlook. Front Oncol. 2015;5:278.

107. Carmena M, Earnshaw WC. The cellular geography of aurora kinases. Nat Rev Mol Cell Biol. 2003;4:842-54.

108. Giles FJ, Swords RT, Nagler A, Hochhaus A, Ottmann OG, Rizzieri DA, Talpaz M, Clark J, Watson P, Xiao A, et al. MK-0457, an aurora kinase and BCR-ABL inhibitor, is active in patients with BCR-ABL T315I leukemia. Leukemia. 2013;27:113-7.

109. Mancini M, Leo E, Aluigi M, Marcozzi C, Borsi E, Barbieri E, Santucci MA. Gadd45a transcriptional induction elicited by the aurora kinase inhibitor MK-0457 in Bcr-Abl-expressing cells is driven by Oct-1 transcription factor. Leuk Res. 2012;36:1028-34.

110. Seymour JF, Kim DW, Rubin E, Haregewoin A, Clark J, Watson P, Hughes T, Dufva I, Jimenez JL, Mahon FX, et al. A phase 2 study of MK-0457 in patients with BCR-ABL T315I mutant chronic myelogenous leukemia and philadelphia chromosome-positive acute lymphoblastic leukemia. Blood Cancer J. 2014:4:e238.

111. Hielke J Meulenbeld RHM, Verweij J, de Wit R, de Jonge MJA. Danusertib, an aurora kinase inhibitor. Expert Opin Investig Drugs. 2012;21:383-93.

112. Artur Gontarewicz SB, Keller G, Colombo R, Graziano A, Pesenti E, Benten D, Bokemeyer C, Fiedler W, Moll J"r, Tim H B"m. Simultaneous targeting of aurora kinases and Bcr-Abl kinase by the small molecule inhibitor PHA739358 is effective against imatinib-resistant BCR-ABL mutations including T315I. Blood. 2008;11:4355-64.

113. Borthakur G, Dombret H, Schafhausen P, Brummendorf TH, Boissel N, Jabbour E, Mariani M, Capolongo L, Carpinelli P, Davite C, et al. A phase I study of danusertib (PHA-739358) in adult patients with accelerated or blastic phase chronic myeloid leukemia and Philadelphia chromosomepositive acute lymphoblastic leukemia resistant or intolerant to imatinib and/or other second generation c-ABL therapy. Haematologica. 2015;100: 898-904.

114. Long ZJ, Wang LX, Zheng FM, Chen JJ, Luo Y, Tu XX, Lin DJ, Lu G, Liu Q. A novel compound against oncogenic aurora kinase a overcomes imatinib resistance in chronic myeloid leukemia cells. Int J Oncol. 2015:46:2488-96.

115. Wang LX, Wang JD, Chen JJ, Long B, Liu LL, Tu XX, Luo Y, Hu Y, Lin DJ, Lu G, et al. Aurora a kinase inhibitor AKl603 induces cellular senescence in chronic myeloid leukemia cells harboring T315I mutation. Sci Rep. 2016;6:35533.

116. Kelly KR, Ecsedy J, Medina E, Mahalingam D, Padmanabhan S, Nawrocki ST, Giles FJ, Carew JS. The novel aurora a kinase inhibitor MLN8237 is active in resistant chronic myeloid leukaemia and significantly increases the efficacy of nilotinib. J Cell Mol Med. 2011;15:2057-70.

117. Tanaka R, Squires MS, Kimura S, Yokota A, Nagao R, Yamauchi T, Takeuchi M, Yao $H$, Reule M, Smyth T, et al. Activity of the multitargeted kinase inhibitor, AT9283, in imatinib-resistant BCR-ABL-positive leukemic cells. Blood. 2010; 116:2089-95.
118. Gandhi V, Plunkett W, Cortes JE. Omacetaxine: a protein translation inhibitor for treatment of chronic myelogenous leukemia. Clin Cancer Res. 2014;20: 1735-40.

119. Allan EK, Holyoake TL, Craig AR, Jorgensen HG. Omacetaxine may have a role in chronic myeloid leukaemia eradication through downregulation of Mcl-1 and induction of apoptosis in stem/progenitor cells. Leukemia. 2011; 25:985-94.

120. Cortes J, Digumarti R, Parikh PM, Wetzler M, Lipton JH, Hochhaus A, Craig AR, Benichou AC, Nicolini FE, Kantarjian HM, Omacetaxine 203 Study G. Phase 2 study of subcutaneous omacetaxine mepesuccinate for chronicphase chronic myeloid leukemia patients resistant to or intolerant of tyrosine kinase inhibitors. Am J Hematol. 2013;88:350-4.

121. Cortes JE, Nicolini FE, Wetzler M, Lipton JH, Akard L, Craig A, Nanda N, Benichou AC, Leonoudakis J, Khoury HJ, et al. Subcutaneous omacetaxine mepesuccinate in patients with chronic-phase chronic myeloid leukemia previously treated with 2 or more tyrosine kinase inhibitors including imatinib. Clin Lymphoma Myeloma Leuk. 2013;13:584-91.

122. Cortes J, Lipton JH, Rea D, Digumarti R, Chuah C, Nanda N, Benichou AC, Craig AR, Michallet M, Nicolini FE, et al. Phase 2 study of subcutaneous omacetaxine mepesuccinate after TKI failure in patients with chronic-phase CML with T315I mutation. Blood. 2012;120:2573-80.

123. Ilander M, Hekim C, Mustjoki S. Immunology and immunotherapy of chronic myeloid leukemia. Curr Hematol Malig Rep. 2014;9:17-23.

124. Yangqiu Li CLaCAS: New insights into antigen specific immunotherapy for chronic myeloid leukemia. Cancer Cell Int 2012, 12:1-8.

125. Rojas JM, Knight K, Wang L, Clark RE. Clinical evaluation of BCR-ABL peptide immunisation in chronic myeloid leukaemia: results of the EPIC study. Leukemia. 2007:21:2287-95.

126. Jain N, Reuben JM, Kantarjian H, Li C, Gao H, Lee BN, Cohen EN, Ebarb T, Scheinberg DA, Cortes J. Synthetic tumor-specific breakpoint peptide vaccine in patients with chronic myeloid leukemia and minimal residual disease: a phase 2 trial. Cancer. 2009;115:3924-34.

127. Bocchia M, Gentili S, Abruzzese E, Fanelli A, Iuliano F, Tabilio A, Amabile M, Forconi F, Gozzetti A, Raspadori D, et al. Effect of a p210 multipeptide vaccine associated with imatinib or interferon in patients with chronic myeloid leukaemia and persistent residual disease: a multicentre observational trial. Lancet. 2005;365:657-62.

128. Monica Bocchia MD, Ippoliti M, Amabile M, Breccia M, Iuliano F, Vignetti M, Gugliotta G, Rossi AR, Alimena G, Aprile L, Gaidano G, Nicoli P, Trawinska MM, Bassan R, Turri D, Cannella L, Luciano L, Gozzetti A, Rondoni M, Rosti G, Martinelli G, Baccarani M, Lauria F. BCR-ABL derived peptide vaccine in chronic myeloid leukemia patients with molecular minimal residual disease during Imatinib: interim analysis of a phase 2 multicenter GIMEMA CML working party trial. Blood. 2009;114:648.

129. Bocchia M, Defina M, Aprile L, Ippoliti M, Crupi R, Rondoni M, Gozzetti A, Lauria F. Complete molecular response in CML after p210 BCR-ABL1-derived peptide vaccination. Nat Rev Clin Oncol. 2010;7: $600-3$.

130. Rosenfeld C, Cheever MA, Gaiger A. WT1 in acute leukemia, chronic myelogenous leukemia and myelodysplastic syndrome: therapeutic potential of WT1 targeted therapies. Leukemia. 2003;17:1301-12.

131. Oji Y, Oka Y, Nishida S, Tsuboi A, Kawakami M, Shirakata T, Takahashi K, Murao A, Nakajima $H$, Narita M, et al. WT1 peptide vaccine induces reduction in minimal residual disease in an Imatinib-treated CML patient. Eur J Haematol. 2010;85:358-60.

132. Smith BD, Kasamon YL, Kowalski J, Gocke C, Murphy K, Miller CB, GarrettMayer E, Tsai HL, Qin L, Chia C, et al. K562/GM-CSF immunotherapy reduces tumor burden in chronic myeloid leukemia patients with residual disease on imatinib mesylate. Clin Cancer Res. 2010;16:338-47.

133. Inna Lindner MAK-D, Ayala E, Kolonias D, Carlson LM, Beazer-Barclay Y, Scherf U, Hnatyszyn JH, Lee KP. Induced dendritic cell differentiation of chronic myeloid leukemia blasts is associated with down-regulation of BCRABL. J Immunol. 2003;171:1780-91.

134. Litzow MR, Dietz AB, Bulur PA, Butler GW, Gastineau DA, Hoering A, Fink SR, Letendre L, Padley DJ, Paternoster SF, et al. Testing the safety of clinicalgrade mature autologous myeloid DC in a phase I clinical immunotherapy trial of CML. Cytotherapy. 2006;8:290-8.

135. Westermann J, Kopp J, van Lessen A, Hecker AC, Baskaynak G, le Coutre P, Dohner K, Dohner H, Dorken B, Pezzutto A. Vaccination with autologous non-irradiated dendritic cells in patients with bcr/abl+ chronic myeloid leukaemia. Br J Haematol. 2007;137:297-306. 
136. Nishino M, Ramaiya NH, Hatabu H, Hodi FS. Monitoring immune-checkpoint blockade: response evaluation and biomarker development. Nat Rev Clin Oncol. 2017;

137. Mumprecht S, Schurch C, Schwaller J, Solenthaler M, Ochsenbein AF. Programmed death 1 signaling on chronic myeloid leukemia-specific T cells results in T-cell exhaustion and disease progression. Blood. 2009; 114:1528-36.

138. Riether C, Gschwend T, Huguenin AL, Schurch CM, Ochsenbein AF. Blocking programmed cell death 1 in combination with adoptive cytotoxic T-cell transfer eradicates chronic myelogenous leukemia stem cells. Leukemia. 2015;29:1781-5.

139. Schutz C, Inselmann S, Sausslele S, Dietz CT, Mu Ller MC, Eigendorff E, Brendel CA, Metzelder SK, Bru Mmendorf TH, Waller C, et al. Expression of the CTLA-4 ligand CD86 on plasmacytoid dendritic cells (pDC) predicts risk of disease recurrence after treatment discontinuation in CML. Leukemia. 2017;31:829-36.

Submit your next manuscript to BioMed Central and we will help you at every step:

- We accept pre-submission inquiries

- Our selector tool helps you to find the most relevant journal

- We provide round the clock customer support

- Convenient online submission

- Thorough peer review

- Inclusion in PubMed and all major indexing services

- Maximum visibility for your research

Submit your manuscript at www.biomedcentral.com/submit
Biomed Central 